\title{
TERRITÓRIOS NÃO-CAPITALISTAS E REPRODUÇÃO DO CAPITAL: o papel de Rosa Luxemburgo
}

\author{
Msc. César Ricardo Simoni Santos \\ Doutorando do Programa de Pós-Graduação em Geografia Humana - USP \\ Cidade Universitária, Av. Lineu Prestes, 338 - CEP 05.508-900, São Paulo (SP), Brasil
}

Tel.: (11) 3091.3769 - cesar_simoni@hotmail.com

\begin{abstract}
RESUMO
Novamente, assim como já havia feito Rosa Luxemburgo, aparecem autores que defendem a necessária permanência de territórios de formação não-capitalista como recurso para a expansão e reprodução do capital nas mais diversas escalas em que o processo pode atuar. Essas idéias são úteis para a compreensão da dinâmica espacial do capitalismo, e a maioria delas se escora na própria teoria formulada por Rosa Luxemburgo. Mesmo não concordando com a necessidade de permanência desses territórios não capitalistas, é preciso reconhecer que parte dos processos de expansão capitalista se justifica por mecanismos desse tipo. Apesar de não podermos atribuir exclusividade a essa teoria na interpretação da reprodução capitalista a partir do espaço, como quis Luxemburgo e ainda conclama Rosa Tello Robira, é inegável que a utilização de territórios de formação tipicamente não-capitalistas atuou e vem atuando no avanço dos processos que resultam na acumulação de capital.
\end{abstract}

Palavras-chave: Acumulação de capital; Rosa Luxemburgo; territórios não-capitalistas.

\begin{abstract}
As Rosa Luxemburg had done, some authors still defend nowadays the necessary permanence of non-capitalist forms of territories as resources to capital expansion and capital reproduction, in the various stages of the process. These ideas are useful to the comprehension of the spacious dynamics of capitalism, and most of them are founded on the same theory formulated by Rosa Luxemburg herself. Even though we do not agree with the necessity of maintaining non-capitalist territories, it's important to recognize that part of the capitalist expansion process can be justified by mechanisms of this kind. Despite the fact that we cannot attribute solely to this theory the interpretation of capitalist reproduction, from a spacious perspective, as claimed Luxemburg and still does Rosa Tello Robira, it's undeniable that the use of typically non-capitalist formed territories has acted upon the development of the processes which usually result in capital accumulation.
\end{abstract}

Key words: Capital accumulation; Rosa Luxemburg; non-capitalist territories.

\section{RÉSUMÉ}

À la manière de Rosa Luxemburg, apparaissent de nouveaux auteurs qui défendent la nécessaire permanence de territoires de formation non-capitaliste comme ressource pour l'expansion et la reproduction du capital aux échelles les plus diverses du processus. Ces idées servent à la compréhension de la dynamique spatiale du capitalisme et s'appuient, pour une large part, sur la théorie formulée par Rosa Luxemburg. Même sans être d'accord avec la nécessité de permanence de ces territoires non-capitalistes, il faut reconnaître qu'un certain nombre de processus d'expansion capitaliste se justifie par des mécanismes de ce type. Quoique nous ne puissions attribuer l'exclusivité à cette théorie dans l'interprétation de la reproduction capitaliste à partir de l'espace, comme l'a expliqué Rosa Luxemburg dans sa théorie, reprise par Rosa Tello Robira, mais il est incontestable que l'utilisation de territoires de formation typiquement non-capitaliste a joué et continue à jouer un rôle très important dans l'avancée des processus, donnant lieu à l'accumulation de capital.

Mots-clés: Accumulation de capital; Rosa Luxemburg; territoires non-capitalistes.

\section{INTRODUÇÃO}

Mais recentemente, o debate sobre a dinâmica espacial do capitalismo voltou a habitar a agenda de geógrafos, economistas, sociólogos, arquitetos, urbanistas e historiadores. Bastante impulsionada pela repercussão das recentes produções de Giovanni Arrighi e David Harvey, a retomada de um debate sobre o imperialismo em épocas recentes vem acompanhada de uma teoria geográfica do capitalismo, inseparável de uma compreensão do atual modo de reprodução social. No entanto, guardando, inclusive nesse aspecto, muita semelhança com os termos propostos em outras épocas, tensões e disputas se desenham no já bastante agitado cenário de atividade intelectual que definiu os contornos dessa retomada temática. 
No interior do debate marxista, essa questão foi crucial já no início do século XX. O debate sobre o imperialismo encontrou em Rosa Luxemburgo e Lênin dois opositores que elevaram a primeiro plano o problema do comportamento e da dinâmica espaciais do modo de produção capitalista. Toda essa herança é resgatada no fim desse mesmo século e início do século XXI, talvez por força das circunstâncias críticas que abalavam a maior potência imperialista até o momento, sendo essa a mesma condição que se vivia à época de Rosa e Lênin. Em situações críticas os processos de dominação se desvelam e saltam aos olhos, despidos de suas falsas justificativas.

A produção do conhecimento no interior da ciência geográfica não ignorou essas evidências e anteparos deixados por outra época. Ela partiu para uma interpretação dos fatos presentes adotando como perspectiva crítica o desvelamento das estratégias espaciais de exploração e expropriação embutidas no conjunto do arsenal reprodutivo capitalista. Com isso, pretende-se não simplesmente conhecer o funcionamento dos mercados mais a fundo, mas também apontar para as profundas conseqüências de uma dinâmica predatória que consome configurações e arranjos espaciais de diversos tipos. No entanto, sobre essa questão repousa uma tensão quase completamente silenciada. Em 2005, Rosa Tello Robira escreve um artigo afirmando a necessidade de territórios de formação não-capitalista para os processos de reprodução capitalista. Robira extrai essa conclusão da leitura do texto de David Harvey. Equivocadamente, a autora atribui a Harvey uma conclusão que ele mesmo havia atribuído à Rosa Luxemburgo. Podemos concordar, ao menos provisoriamente, com a interpretação que Harvey tem da teoria de Luxemburgo, mas não podemos nos coadunar com a idéia de que, também para Harvey, "o capital necessita de territórios que permaneçam obrigatoriamente em 'situação não-capitalista' para superar suas próprias crise de superacumulação", como diz Rosa Tello Robira (2005, p. 09). Apesar da evidência do desvio que comete na interpretação das idéias de Harvey, a autora lança luz sobre uma questão silenciada com o debate do início do século XX.

Ao partir da necessidade de permanência dos territórios não-capitalistas como condição para a reprodução do capital, Rosa Tello se aproxima mais de Rosa Luxemburgo do que propriamente de Harvey - ou, ao menos, da interpretação que Harvey tem de Luxemburgo. Mesmo David Harvey (1990, 2004 e 2005) reconhece a validade dos esquemas apresentados por Luxemburgo, apesar de superá-los ou mesmo ultrapassá-los no conjunto de sua obra, de tal forma que seja obrigado a negar essa condição espacial como sumariamente obrigatória para a reprodução capitalista. Mas de onde parte essa necessidade, captada por Harvey, na teoria de Rosa Luxemburgo? Como Luxemburgo chega a esse mecanismo da reprodução espacial do capitalismo? Acompanharemos neste artigo parte do esforço para responder essas questões.

\section{A SOLUÇÃO DO PROBLEMA A PARTIR DA UTILIZAÇÃO DOS ESPAÇOS NÃO- CAPITALISTAS}

Rosa Tello Robira acredita, e fez um louvável esforço para demonstrá-lo, que as formas de utilização e apropriação do espaço pelos "processos moleculares de acumulação do capital" estão no centro das estratégias reprodutivas do capitalismo (ROBIRA, 2005). No entanto, a autora, ao tentar demonstrar toda a importância das configurações espaciais para a reprodução do capital, permanece presa a uma forma específica em que o processo pode tomar corpo. Para ela, a necessidade de contínua expansão do capital somente pode ser satisfeita, tendo em vista a continuidade dos processos de acumulação capitalista, a partir da utilização progressiva de um estoque de reservas não-capitalistas manifestos naquilo que chama de "territórios reserva". Segundo ela:

Considerando os territórios metropolitanos aqueles espaços onde se intensificam 'os processos moleculares de acumulação de capital', é possível supor que para que continuem a produzir tal acumulação devem ser territórios capazes de manter no seu interior territórios 'não-capitalistas' que, na forma de reservas, tenham a função de resolver de maneira eficaz as sucessivas crises de expansão/ acumulação do próprio sistema territorial metropolitano (ROBIRA, 2005, p. 10). 
Nesse sentido, a partir de sua concepção do processo, a expansão, a acumulação, o "desenvolvimento" e toda a história do capitalismo estariam circunscritos à existência de tais "reservas" territoriais de formação "não-capitalista", como um estoque limitado que abastecerá por tempo definido o próprio mecanismo de reprodução do capital e determinará, em seu esgotamento, o fim das possibilidades de acumulação. Essa posição aproxima a nossa autora de outra, que, coincidentemente, atendia pelo mesmo pré-nome. Rosa Luxemburgo (1985), a partir da produção de sua obra de referência, A Acumulação do Capital, chegou a conclusões similares. Apesar de Rosa Luxemburgo não tematizar diretamente a problemática espacial para os processos de acumulação do capital, não é difícil extrair de suas conclusões essa dimensão indissociável do processo. Para ela a realidade dos processos de acumulação capitalista deve contar sempre com elementos exteriores à lógica interna do próprio capital. A isso ela atribui a necessidade de manutenção dos "mercados externos" ou "terceiras pessoas". Para Rosa Luxemburgo, os "mercados externos" não devem ser confundidos com aqueles de que fala Lênin (1979). Apesar do impulso crítico que move o capital para fora de si poder ser identificado com relativa semelhança nas descrições de Lênin e Rosa Luxemburgo, os pressupostos dessa formação capitalista necessariamente crítica são absolutamente diversos e partem de interpretações sobre o esquema de reprodução apresentado por Marx (1989) encarnecidamente divergentes. Para Rosa Luxemburgo, os "mercados externos" não têm a mesma configuração que assumem em Lênin ou em grande parte da literatura econômica. Antes de se colocar como espaços extranacionais, eles são externos na medida em que não pertencem a um tipo de mercado elaborado pelas próprias estruturas reprodutivas do capital; ou seja, antes de qualquer coisa, são mercados não-capitalistas inseridos historicamente nos processos de acumulação do capital. Segundo Rosa Luxemburgo, "mercado externo é para o capital o meio social não-capitalista que absorve seus produtos e lhe fornece elementos produtivos e força de trabalho" (LUXEMBURGO, 1985, p. 251).

Desse ponto de vista econômico, a Alemanha e a Inglaterra constituem, em sua troca recíproca, uma para a outra, mercados capitalistas internos, enquanto as trocas entre a indústria alemã e seus produtores ou consumidores camponeses alemães representam, para o capital alemão, relações de mercado externo (LUXEMBURGO, 1985, p. 251).

É somente por essa idéia que, para Rosa Luxemburgo, "o mercado interno e o mercado externo desempenham, sem dúvida, papel importante e inconfundível na evolução do desenvolvimento capitalista, não como conceitos de Geografia Política, mas como conceitos de Economia Social" (LUXEMBURGO, 1985, p. 251). Nesse aspecto, as duas autoras parecem convergir.

Mas as semelhanças não se esgotam na compreensão da natureza de tais mercados ou territórios não-capitalistas. Para Rosa Luxemburgo, da mesma forma em que para Rosa Tello Robira, a realização da mais-valia e a solução das crises de realização devem contar necessariamente com os enxertos de algum tipo de reserva externa ao escopo da economia capitalista - e essa reserva, tanto na apresentação de Rosa Tello Robira quanto nos esquemas de Rosa Luxemburgo, assumem indissociavelmente uma dimensão espacial. Há, aqui, portanto, uma premissa compartilhada entre as duas: a de que, para resolver suas próprias crises de realização, o capitalismo avança sobre os campos dos mercados, espacialmente definidos, de formação ainda não-capitalista.

\section{O AVANÇO SOBRE FORMAÇÕES TERRITORIAIS NÃO-CAPITALISTAS}

Os arranjos institucionais, a promoção da infra-estrutura de circulação e produção ou a criação de uma base de fomentos, como fatores que compõem a base de uma política de Estado, funcionam como elementos diferenciadores que atuam na escala do território. Claro está que a natureza e o posicionamento são fatores de diferenciação e atuam tanto quanto outros na promoção ou contenção do desenvolvimento de determinadas características numa economia de mercado. Isso tudo faz parte da dimensão geográfica inalienável da teoria do capitalismo e aparece na condição de 
atributo monopolizável segundo o modo de agir de uma poderosa política que surge no contexto de uma intrincada disputa interestatal. É por isso que Rosa Luxemburgo admite, já no prefácio de A Acumulação do Capital, de 1912, "que este trabalho, além de apresentar um interesse puramente teórico, também adquire importância para a luta prática na qual nos empenhamos contra o imperialismo" (LUXEMBURGO, 1985, p. 03).

À medida que o impulso à expansão capitalista sobre áreas de formação não-capitalista se manifesta como recurso da dominação interestatal, tais unidades político-territoriais vão assumindo uma feição mais homogênea, tal como foi possível falar das "potências industriais" no fim do século XIX e início do XX. Nesse sentido, o centro se expande e tende a incluir novos espaços centrais, assim como também deverá fazer surgir novas periferias, como decorrência de sua própria expansão. Mas tal processo não permanece restrito à escala global, ou nacional. Podemos adotar aqui também, como exemplo, o avanço dessas formações capitalistas sobre a periferia urbana. $\mathrm{Na}$ mesma medida em que o processo avança, o escasseamento dessas reservas territoriais não-capitalistas vai sugerindo os limites de um crescimento contínuo no interior dessas unidades territoriais. A definição territorial de regiões sumariamente "desenvolvidas" em termos capitalistas exige um novo movimento centrífugo do capital que pode se dar do centro às periferias urbanas, da "região concentrada" para o interior do mesmo país ou do país ao restante do mundo não-colonizado. $\mathrm{O}$ processo de colonização e das práticas imperialistas sugere, para Rosa Luxemburgo, este mesmo movimento, como podemos ver.

Se com o desenvolvimento internacional do capital a capitalização da mais-valia se torna a cada instante mais urgente e precária, de modo absoluto enquanto massa, bem como em relação à mais-valia, essa base de capital constante e variável se torna cada vez maior. Daí o fato contraditório de os antigos países capitalistas representarem, um para o outro, mercados cada vez maiores e imprescindíveis, e se digladiarem ao mesmo tempo mais intempestivamente na qualidade de concorrentes e em função de suas relações com os países não-capitalistas (LUXEMBURGO, 1985, pp. 251-252).

Daí a gênese do processo que representou, no fim do século XIX e início do XX, "não uma superação da intensa competição intercapitalista que marcara a Grande Depressão de 1873-96, porém uma mudança de seu locus primário da esfera das relações interempresariais para a das relações interestatais" (ARRIGHI, 1996, p. 277). É por isso que, "para a autora, as bases econômicas do imperialismo se encontrariam no próprio processo de acumulação de capital" (MIGLIOLI, 2004, p.182) e não, como para Lenin (1979), na manifestação de uma fase avançada a que o desenvolvimento do capitalismo conduziu historicamente.

É por esse comportamento unívoco, então, considerado tanto por Rosa Luxemburgo quanto por Rosa Tello, que o limite dos processos de acumulação, para ambas, somente pode ser dado de fora; trata-se, nesse caso, de um processo que encontra seus limites de progressão/expansão na elaboração exclusiva de limites externos. A negatividade do processo de metropolização, pressuposta por Rosa Tello Robira, é externa ao próprio processo de metropolização, assim como é externa aos processos capitalistas que interferem na produção do espaço urbano; trata-se de uma negatividade, logicamente anterior e historicamente determinante. Dessa forma, é a aniquilação de tais "reservas" territoriais "não-capitalistas" que estaria na base do processo crítico de reprodução e que o levaria a seu fim.

Contraditoriamente, no entanto, a partir desses pressupostos, não há como se chegar a uma compreensão das crises como processos internamente elaborados, a partir das contradições do próprio modo de produção capitalista, visto que a pressuposição da falta absoluta de elementos exteriores exerce o papel de elemento crítico crucial em tal interpretação acerca dos mecanismos de reprodução. Assim, também, o ponto de partida da análise dos processos críticos de reprodução do capital não pode estar na elaboração das crises de sobreacumulação, como crises definidas no interior, pelo e para o próprio modo de produção capitalista, como fez Rosa Tello Robira, mas somente na escassez de demanda efetiva, como um fator não estrutural e um elemento determinado 
de fora do corpo lógico do próprio capitalismo, como fez Rosa Luxemburgo. Uma raiz limitada de compreensão do processo de formação das crises somente pode conduzir a um universo de possibilidades de solução igualmente limitado.

Um problema que decorre dessa perspectiva, no entanto, é a possível crença no fato de que os limites da reprodução capitalista, como postos essencialmente de fora, se manifestam somente na extinção dos territórios de tipo não-capitalista. Logo, um corolário possível desse argumento pode se manifestar na perspectiva de que a evolução e o envolvimento cada vez maior de territórios anteriormente não-capitalistas nos próprios processos de produção e reprodução da mais-valia significam univocamente um processo de caráter progressista e positivo, que apontam para o fim da exploração capitalista, na mesma medida em que a preservação de tais territórios representaria a condenação de todo o globo ainda ao longo domínio do capital. Qualquer resistência ao processo é, nesse sentido, considerada essencialmente conservadora.

Rosa Luxemburgo vê, portanto, um processo de avanço do capitalismo no sentido da tomada de toda a superfície terrestre, como podemos notar pelos exemplos dados pela autora. Esse avanço se dá pela busca de suprimento dos mercados capitalistas, com a conquista da demanda necessária, das matérias-primas e da força de trabalho não correntemente produzidas no interior desses mesmos mercados. Esse processo, por sua vez, resulta no avanço da destruição de formações sociais nãocapitalistas em novos territórios . É por isso que, para Rosa Luxemburgo,

o capital não pode existir sem contar com a presença dos meios de produção e da força de trabalho de toda parte; para o desenvolvimento pleno de seu movimento de acumulação ele necessita de todas as riquezas naturais e da força de trabalho de todas as regiões do globo. Uma vez que de fato e em sua maioria estas se encontram ligadas às formas de produção pré-capitalistas - que constituem o meio histórico de acumulação do capital -, daí resulta a tendência incontida do capital de apossar-se de todas as terras e sociedades (LUXEMBURGO, 1985, pp. 250-251).

Por isso, ela vê, naquilo que, segundo ela, Marx descreve como sendo o momento inicial, histórico e lógico, do capitalismo, a matéria de uma recorrência sem fim. A repetição da separação dos trabalhadores de seus meios de produção e a implantação de arranjos institucionais que redundam na concentração da propriedade, entre outros, indicam para Rosa Luxemburgo que há, no processo de colonização e avanço do capital sobre áreas ainda relativamente preservadas, uma reposição continuada daquilo que Marx chamou de acumulação primitiva. Em sintonia com a crítica mais geral apresentada em A Acumulação do Capital, ela aponta novamente o limite da concepção marxiana sobre os processos de reprodução capitalista. Agora, no que diz respeito à concepção presente na elaboração o conceito de acumulação primitiva, Luxemburgo enfatiza que "os processos que Marx apresenta apenas ilustram a gênese, o nascimento do capital, caracterizando as dificuldades iniciais do modo de produção capitalista depois de libertar-se da tutela da sociedade feudal" (LUXEMBURGO, 1985, p. 250). Apesar de reconhecer que "a pilhagem que ocorre nos países coloniais por parte do capital europeu tem papel relevante na descrição feita por Marx", ela destaca: "tudo isso, note-se bem, com referência à análise da chamada 'acumulação primitiva', no entanto" (LUXEMBURGO, 1985, p. 250). Com isso, Rosa Luxemburgo quis apontar mais um aspecto da teoria marxiana que supostamente confirma sua própria interpretação acerca da tese presente em O Capital, ou seja, a de que as idéias de Marx preconizam, ao final, um modo de produção coerente e fechado em si mesmo.

\section{ACUMULAÇÃO PRIMITIVA, COLONIZAÇÃO E IMPERIALISMO}

Para Rosa Luxemburgo, a expansão do capitalismo, dada a sua incoerência estrutural, está fadada a reproduzir eternamente aquilo que Marx chamou de "acumulação primitiva", assim como os mecanismos de colonização. Três termos se interconectam aqui: acumulação primitiva, colonização/ imperialismo e expansão das forças produtivas. Numa apreciação do problema, por Jorge Miglioli,

Mercator - volume 9, número 18, 2010: jan./abr. 
Baseando-nos unicamente no livro sobre A Acumulação do Capital, podemos dizer que Rosa Luxemburgo apresenta da seguinte maneira o problema do imperialismo. O processo de acumulação capitalista requer, desde o princípio, a existência de mercados externos onde deve ser realizada uma parte da mais-valia. Assim, desde suas origens, o capitalismo luta pela conquista de novos mercados e pela preservação dos existentes. Daí por que a fase histórica definida por Marx como sendo de "acumulação primitiva" é, para Rosa Luxemburgo, apenas o retrato, delimitado num determinado período de tempo, do processo normal de acumulação. Do mesmo modo, a fase imperialista não é uma decorrência da luta capitalista por novos mercados numa época específica em que o capitalismo, atingindo sua maturidade, começa a encontrar problemas para realizar internamente a sua mais-valia - porque essa luta vem desde as origens do capitalismo, é comum a todas as fases do processo de acumulação (MIGLIOLI, 2004, pp. 209-210).

Deste modo, Rosa Luxemburgo define com bastante clareza qual é a sua posição no debate com Lenin. Apesar de Lenin somente ter escrito Imperialismo: fase superior do capitalismo em 1916, 4 anos, portanto, após Rosa Luxemburgo ter escrito A Acumulação do Capital, o posicionamento diante do problema do imperialismo entre os marxistas, naquele momento, era uma questão crucial. Para Lenin, o imperialismo é a manifestação de um momento particular no curso de desenvolvimento do capitalismo. Ele está associado à era do capital monopolista e do expansionismo financeiro. A publicação do livro de Hilferding, O Capital Financeiro, exerceu grande influência entre os marxistas, inclusive sobre Lenin, apesar de suas recorrentes críticas ao autor em seu livro sobre o imperialismo. No entanto, Rosa Luxemburgo pensa o problema de forma diferente. Ela entende o Imperialismo, apesar de muito pouco falar sobre ele, como uma manifestação daquele impulso original do capitalismo, segundo o qual a colonização de novas áreas, de territórios nãocapitalistas, se coloca como a única forma de se realizar a mais-valia produzida. Nesse sentido, o imperialismo seria simplesmente a manifestação em escala internacional da mesma tendência apresentada em escalas mais reduzidas, como no interior de um território específico, por exemplo. Para Rosa Luxemburgo, o deslocamento geográfico do capital é um dado da própria realização do capital e se manifesta sob a forma da exploração e/ou colonização de territórios não-capitalistas em qualquer escala espacial na qual possam ocorrer os processos de reprodução capitalista.

Dessa forma, as semelhanças e proximidades entre Rosa Tello Robira e Rosa Luxemburgo ficam mais evidentes. Destacando o processo no "interior dos espaços metropolitanos", e como tal se constituindo "num processo de metropolização", Rosa Tello Robira acredita que:

Poder-se-ia dizer que o processo de metropolização se realiza, ao igual como o de colonização, em primeiro lugar como processo de acumulação primitiva produzindo enormes déficits urbanísticos e diferenças sociais profundas que, como reservas de solo urbano e força de trabalho, alimentam depois, nos momentos em que começam a diminuir as taxas de crescimento demográfico e de expansão urbana, o processo de acumulação da metrópole (ROBIRA, 2005, p. 14).

\section{O EQUÍVOCO DE ROSA LUXEMBURGO}

"O problema dos mercados" se constituía como o grande divisor de águas no debate marxista na passagem do XIX para o XX. Esse patrimônio permaneceu como herança para as atuais gerações. Muitos dos estudos sobre a obra de Marx, ainda hoje, fazem menção ao problema colocado pelo debate entre aqueles que, por um lado, a partir da obra de Marx, puderam ver a harmonia no processo de acumulação, e aqueles que, por outro, no esforço de restauração de uma crítica que parte das contradições inalienáveis do capitalismo, destacaram as fortes tendências ao colapso e à dissolução de tais fatores de ordenação social.

Nas duas vertentes, no entanto, a obra de Marx é mutilada. O "problema dos mercados", tal como ficou conhecido, e sua extensão no interior dos circuitos marxistas partem, por um lado, de um conjunto de interpretações sobre os esquemas de reprodução apresentados no segundo volume de $\mathrm{O}$ 
Capital absolutamente restrito. Tugan-Baranóvski, por exemplo, fez um monumental esforço para demonstrar, contra os populistas, a viabilidade da acumulação capitalista sob diversas condições, simplesmente se utilizando dos esquemas da reprodução ampliada de O Capital. Para isso, TuganBaranóvski sugeriu uma divisão no departamento II, aquele ligado à produção de bens de consumo no esquema de Marx, entre um departamento produtor de bens de consumo para o trabalhador (e, portanto, correspondente ao valor total dos salários pagos pelos capitalistas) e um departamento ligado aos gastos da parte da mais-valia apropriada diretamente pelo capitalista para consumo próprio (artigos de luxo para o consumo do capitalista). O restante da mais-valia produzida, deveria ser realizada pela demanda crescente de bens de capital, e consumida, portanto, produtivamente no Departamento I, produtor de bens de produção. Dessa forma, não só Tugan-Baranóvski, como outros marxistas, pôde encontrar respaldo no capítulo 21 do segundo tomo de O Capital para afirmar a possibilidade de crescimento equilibrado sob domínio do modo de produção capitalista. Rosa Luxemburgo, no outro extremo, acusou Hilferding e Otto Bauer de terem persistido no mesmo equívoco de interpretação do capitalismo que Tugan-Baranóvski. Com isso, Rosa Luxemburgo partia na tentativa de restaurar as contradições e todo o postulado crítico que havia conduzido a exposição de O Capital até o fim do primeiro volume.

Sobre "os motivos que impulsionaram essa crítica":

Henryk Grossmann parece haver acertado quando escreveu: 'foi um grande mérito de Rosa Luxemburgo que, em deliberado contraste e como protesto contra as tentativas de deformação dos que defendiam a tendência do capitalismo à harmonia, ela tenha retornado à idéia fundamental de $\mathrm{O}$ Capital, demonstrando que existe um limite econômico absoluto para o desenvolvimento do modo de produção capitalista' (ROSDOLSKY, 2001, p. 407).

No entanto, Rosa Luxemburgo não entende que o equívoco de seus oponentes teóricos tenha partido de um equívoco anterior, cometido durante a leitura dos textos de Marx por parte desse autores. Por isso ela vai atribuir ao próprio Marx essa possibilidade de interpretação. Isso significa que ela mesma tinha uma interpretação sobre os esquemas de Marx que comprometia o seu ponto de vista crítico sobre a acumulação capitalista, e foi isso que a obrigou a desenvolver, simultaneamente, uma crítica ao esquema de reprodução ampliada de O Capital. Para Rosa Luxemburgo,

A análise de Marx da reprodução social, no segundo volume de O Capital, pareceu mostrar que a acumulação de capital poderia continuar indefinidamente e sem limites. Isso pareceu pôr Marx em acordo com Ricardo e com a Lei de Say, segundo a qual não há uma quantidade de capital que não se possa empregar em um país, posto que o único limite imposto à demanda global é aquele imposto pela própria produção (HARVEY, 1990, p. 87).

\section{Isso ocorreu porque:}

Em lugar de 'examinar o esquema da reprodução de Marx nos marcos do sistema global do próprio Marx, e especialmente sua teoria da acumulação, [...] [ela] submeteu-se involuntariamente à influência daqueles que desejava combater, acreditando que o esquema de Marx admite de fato uma acumulação ilimitada, $[\ldots]$ conforme a teoria de Tugan-Baranóvski'. Como ela mesma opinava que 'do esquema da reprodução de Marx resulta a possibilidade de acumulação ad infinitum, que Tugan, Hilferding e depois Otto Bauer deduziram corretamente essa idéia a partir do esquema, abandonou o esquema de Marx para salvar a idéia da derrocada, resultante do primeiro tomo de O Capital' (ROSDOLSKY, 2001, p. 407).

Esse ponto de vista crítico com relação aos esquemas da reprodução de Marx se fundamenta numa perspectiva equivocada acerca do papel que tais esquemas representam no conjunto da obra desse autor. "Embora Rosa Luxemburgo reconheça que as concepções de Marx acerca da acumulação de capital se estendem por todos os três volumes do Capital, ela passa a tratar o esquema de reprodução ampliada como se fosse a teoria da acumulação de Marx" (MIGLIOLI, 2004, p. 182). 
Essa substituição aleatória promove uma confusão entre o recurso a uma "sociedade especificamente capitalista" e o "capital em sua manifestação histórica concreta". Marx recorre a esquemas generalizantes a fim de demonstrar as insuficiências lógicas do próprio regime de acumulação capitalista. Por isso, em diversas passagens de sua obra, Marx aponta para o funcionamento de uma sociedade inteiramente capitalista.

Rosa Luxemburgo entendeu mal o papel desempenhado, na obra de Marx, pelo modelo de uma sociedade puramente capitalista. Não compreendeu que se tratava apenas de um princípio heurístico, útil para ajudar a mostrar as tendências evolutivas do modo de produção capitalista, libertadas 'de qualquer circunstância acessória perturbadora'. (Desse ponto de vista, as intermináveis discussões sobre a possibilidade histórica de existir ou não uma sociedade puramente capitalista são completamente irrelevantes.) O objetivo desse procedimento metodológico é claro. Se até mesmo sob as premissas mais severas - ou seja, no interior do modelo abstrato de uma sociedade puramente capitalista - é possível realizar a mais-valia e acumular capital (dentro de certos limites), então não há necessidade teórica de buscar fatores externos, como o comércio exterior, a existência de 'terceiras pessoas', a intervenção do Estado etc. Nesse sentido, o modelo abstrato de Marx suportou o teste (ROSDOLSKY, 2001, p. 407).

Rosa Luxemburgo não concebe, nem ao menos como recurso teórico, a possibilidade de uma acumulação propriamente capitalista como aquela sugerida a partir dos esquemas da reprodução de Marx. Talvez ela tivesse razão se houvesse a intenção de se explicar o processo de acumulação somente a partir dos esquemas, como fizeram Tugan, Hilferding e Bauer. Mas, os esquemas apresentados por Marx não devem ser confundidos com uma tentativa isolada de compreensão dos mecanismos empíricos de reprodução capitalista. "Ao ignorar isso, Rosa Luxemburgo ignorou que os resultados da análise da reprodução no segundo tomo eram provisórios e precisavam ser completados, nas etapas posteriores da investigação, por análises mais concretas" (ROSDOLSKY, 2001, p. 407).

Jorge Miglioli (2004) sustenta a idéia de que um dos problemas da elaboração de Rosa Luxemburgo diz respeito ao fato de que ela não concebe o "afã de acumular por acumular" e de "produzir por produzir", o que é próprio aos capitalistas em sua condição de personificações do capital. Daqui derivam duas concepções inseparáveis, a respeito dos esquemas apresentados em O Capital, que se elaboram a partir de questionamentos absolutamente estranhos às proposições de Marx. Primeiramente, é por isso que o problema, para Rosa Luxemburgo, se elabora nos termos da escassez de demanda, e, em segundo lugar, é por isso também que soa com tanta estranheza, para ela, o fato de que os esquemas de Marx reproduzam "um circulo vicioso" (LUXEMBURGO, 1985, p. 77).

O esquema de Marx, elaborado para demonstrar a reprodução ampliada do capital, conta com um pressuposto provisório: o de que a sociedade capitalista se pôs completamente sobre a superfície da Terra, sem deixar nenhum vestígio de algo que lhe seja estranho e sem precisar recorrer a quaisquer elementos que lhes sejam exteriores. Diante disso, Rosa Luxemburgo considera estranho o fato de que não haja previsto nos esquemas de Marx nenhuma forma de realização da mais-valia alheia aos departamentos já considerados no processo de produção capitalista. Visto que, em um processo de acumulação, sempre aumenta a parte acumulada da mais-valia, logo deverá aumentar também, para isso, a parte produzida da mais-valia. No entanto, a realização de toda mais-valia produzida somente é consagrada no ato da troca (da venda). Eis que, então, surge a indagação inquieta de Rosa Luxemburgo: quem irá consumir ou gerar a demanda que justificará a produção dessa nova parte de mais-valia? A resposta nós já sabemos: as "terceiras pessoas" ou o "mercado externo".

Quanto mais se produz, maior deve ser a demanda, isso é certo. Mas o que intriga Rosa Luxemburgo é: de onde vem essa demanda, num modo de produção que se reproduz de forma ampliada? Para ela, a idéia de que o crescimento da produção é acompanhado internamente de um relativo crescimento da demanda efetiva não é compatível com o impulso capitalista que resulta no aumento sucessivo da produtividade do trabalho por trabalhador empregado. Para ela, portanto, o aumento da demanda necessário não pode vir do próprio modo de produção. É por isso que, em sua 
interpretação, surge uma tendência que parte do interior do próprio modo de produção capitalista a incorporar, freqüentemente, novos mercados não-capitalistas em seu raio de influência e domínio. É munida dessa certeza que Rosa Luxemburgo vai considerar os esquemas de Marx "um absurdo" (LUXEMBURGO, 1985, p. 77).

Segundo o esquema de Marx, o movimento parte do Departamento I, da produção dos meios de produção. Quem necessita de maior número desses meios de produção? Resposta do esquema: o Departamento II necessita deles para poder fabricar um maior número de meios de consumo pessoal. Mas quem precisa desses meios de subsistência adicionais? O esquema responde: o próprio Departamento I, por empregar agora uma quantidade maior de trabalhadores. Obviamente nos encontramos em um circulo vicioso. Elaborar mais meios de consumo exclusivamente para sustentar maior número de trabalhadores e fabricar mais meios de produção somente para empregar mais trabalhadores é algo absurdo do ponto de vista capitalista (LUXEMBURGO, 1985, p. 77).

Primeiramente, aqui reside um dos pontos nodais da crítica à obra de Luxemburgo. O problema da demanda efetiva está diretamente ligado à insuficiência de sua compreensão sobre o afã de acumular que é próprio do capitalista enquanto personificação do capital. Rosa Luxemburgo, por isso, não abandonou a limitada perspectiva de que o modo de produção capitalista tem como finalidade primeira a produção para a satisfação das necessidades humanas (demanda). Ela freqüentemente inverte o ponto de partida de Marx, pressupondo a necessária anterioridade da demanda para a posterior realização do processo de acumulação em escala ampliada. O desvio de interpretação fica mais evidente quando percebemos que, no conjunto de sua obra, a demanda que deverá dar suporte ao próprio processo de acumulação deve ser resultado de fatores estranhos ao modo de produção capitalista. O problema colocado por Rosa Luxemburgo, nesse sentido, somente poderia estar preso à escassez de demanda, e é nesses termos que pretende resolver os problemas por ela mesma encontrados nos esquemas de reprodução de Marx. Dessa forma, segundo Rosa Luxemburgo, "para que efetivamente haja acumulação, ou seja, para que a produção se amplie, existe mais uma condição - ampliação da demanda real e solvente de mercadorias. A que atribuir, então, essa demanda crescente e constante, sobre a qual se apóia a ampliação progressiva da produção no esquema de Marx?" (LUXEMBURGO, 1985, p. 77). Uma vez em que não pode conceber uma solução a partir do próprio esquema de reprodução ampliada do capital e nem, portanto, do aumento da demanda proporcionado pelos mecanismos de acumulação, ela mesma responde: "para que novos trabalhadores possam trabalhar com novos meios de produção, é necessário que - do ponto de vista capitalista - haja de antemão uma razão para ampliar a produção, uma nova demanda de produtos que se deva elaborar" (LUXEMBURGO, 1985, p. 78). Vemos assim, quase em estado puro, a prioridade conferida ao fator demanda na crítica de Rosa Luxemburgo. Trata-se, nesse caso, de uma anterioridade lógica necessária, um verdadeiro pressuposto da acumulação capitalista. Em seus textos a ampliação da demanda é a condição e a razão mesma pela qual se torna possível acumular. É por isso que, na tentativa de correção ou reelaboração dos esquemas, originalmente considerados por ela como equivocados, "a mais-valia pode ser dividida em três partes":

Uma parte é consumida pelos próprios capitalistas enquanto pessoas, enquanto consumidores individuais; uma segunda parte é investida, transformada em capital [incluída aqui aquela parcela que deve alimentar o consumo dos trabalhadores]; e uma terceira parte (...) deve ser realizada de outro modo, deve ser comprada por outras pessoas. Seria essa terceira parte da mais-valia que justificaria a própria acumulação de capital (MIGLIOLI, 2004, p. 185).

Todo o esquema repensado por Rosa Luxemburgo só encontra razão de existir devido à demanda que lhe é logicamente anterior. "Por que os capitalistas acumulam capital e, com isso, ampliam a produção?" Para Rosa Luxemburgo, "até certo ponto porque aumentam o seu próprio consumo pessoal; mas, fundamentalmente, porque existe uma demanda por essa terceira parte da mais-valia" (MIGLIOLI, 2004, p. 185).

Mercator - volume 9, número 18, 2010: jan./abr. 
A partir do esquema apresentado por Marx, a terceira parte da mais-valia "apresentada" (ou inventada) por Rosa Luxemburgo não encontraria meios de realização, sendo justamente essa a parte responsável, naquelas condições, pelos desdobramentos críticos da acumulação. Rosa Luxemburgo não vê possibilidades de realização dos excedentes capitalistas a partir da apresentação esquemática elaborada por Marx. Procurando, então, encontrar quem deve absorver a parte não consumida e não acumulada da mais-valia produzida, Rosa Luxemburgo descarta como possíveis soluções o aumento da população e o comércio exterior (este último, nos termos de Lênin). Nos Capítulos 8 e 9 de A Acumulação do Capital ela vai procurar saber se Marx oferece uma resposta e assim completa seu esquema ou se não, deixando-o em aberto e inacabado. Evidentemente, acaba por concluir que Marx não pode oferecer essa resposta. Mas, segundo Miglioli, "não poderia ser de outro modo, posto que, para Marx, não existia o problema formulado por ela" (MIGLIOLI, 2004, p. 193).

Quando Rosa Luxemburgo nos põe diante do esquema de reprodução ampliada de Marx e afirma que "obviamente nos encontramos em um círculo vicioso" (LUXEMBURGO, 1985, p. 77), ela se refere às insuficiências apresentadas pelo esquema para apontar uma saída de um processo reprodutivo em ampliação com fim em si mesmo. No capítulo 25 de A Acumulação do Capital, Rosa Luxemburgo volta a insistir nessa crítica. Para ela,

Os operários não podem consumir um centavo a mais além da parte do produto que corresponde ao capital variável. Quem realiza então a mais-valia que cresce sem parar? O esquema responde: são os capitalistas e somente eles. E o que fazem com essa mais-valia crescente? O esquema responde: usam-na para ampliar sua produção cada vez mais. Esses capitalistas são, portanto, fanáticos adeptos da ampliação da produção, por amor à própria ampliação da produção. Mandam construir máquinas novas para, com elas, construírem outras máquinas novas (LUXEMBURGO, 1985, pp. 230-231).

Essa percepção poderia ter se constituído na base de uma poderosa crítica às sociedades de formação capitalista se não estivesse presa e dirigida aos esquemas da reprodução elaborados por Marx. Acreditando ser a falta de finalidade ou o paradoxo uma característica particular do esquema teórico (e não da sociedade), ela não percebeu o potencial crítico que a descoberta dessa circularidade sem fim teria caso fosse utilizada na compreensão dos mecanismos econômicos de reprodução social. Para Marx, esse círculo vicioso é a manifestação do próprio movimento da reprodução ampliada do capital. Segundo Luxemburgo, no entanto,

Daí não resulta uma acumulação de capital, mas uma produção crescente de meios de produção, sem nenhuma finalidade; é necessário ter a ousadia e o amor ao paradoxo de um Tugan-Baranovski para admitir que esse incansável carrossel que se situa no vazio seja um fiel retrato da realidade capitalista e uma conseqüência real da teoria marxista (LUXEMBURGO, 1985, p. 231).

Na crítica ao esquema da reprodução ampliada de Marx, Rosa Luxemburgo pergunta: "por que (...) os capitalistas acumulariam a parte restante da mais-valia? Por que acumular capital apenas para absorver uma parte da mais-valia?" (MIGLIOLI, 2004, p. 184). No entanto, o esquema de Marx, que só hipoteticamente cria essa possibilidade, serve para o efeito de demonstração de uma tendência posta na realidade pelo próprio modo de produção capitalista. Para Marx, o fim da acumulação é o próprio processo de acumulação, numa dinâmica que escraviza o capital e todas as forças que lhe servem no cativeiro da valorização. Não compreender o capitalismo como a origem do afã de acumular por acumular ou de produzir por produzir barra a possibilidade de compreensão de que essa circularidade, que é própria do atual modo de produção, se ponha como a manifestação mais fiel do próprio processo de acumulação. Trata-se do pressuposto social da época mais atual. Realizar a mais-valia, sua produção, portanto, a partir de si mesmo é a condição ideal de reprodução capitalista. Ter de satisfazer demandas e necessidades humanas e sociais gera toda uma ordem de constrangimentos absolutamente indesejadas do ponto de vista do afã pela acumulação. Nesses 
termos, a demanda deve ser, portanto, produzida (interna ou externamente) a partir dos novos arranjos espaciais ou institucionais do capitalismo, e não ser considerada um pressuposto, logicamente anterior, da acumulação. A partir disso, não se pode concordar conscienciosamente com Rosa Luxemburgo a respeito do fato de que "para que haja efetivamente acumulação (...), é necessário que - do ponto de vista capitalista - haja de antemão uma razão para ampliar a produção, uma nova demanda de produtos que se deva elaborar" (LUXEMBURGO, 1985, pp. 77-78). A razão, segundo Marx, é o próprio impulso intrínseco à acumulação e nada o antecede nesse aspecto.

Pode-se notar, a partir daí, que a referida circularidade do esquema da reprodução apresentado por Marx é, na verdade, manifestação da circularidade que é própria do processo de acumulação capitalista. Segundo Jorge Miglioli:

Cabe observar desde logo que não é o argumento do esquema de reprodução ampliada que gira em círculos, mas sim a economia capitalista, à qual o esquema se aplica - fato este que, por incrível que pareça, Rosa Luxemburgo, se recusa a reconhecer. Os capitalistas acumulam capital e, assim fazendo, ampliam a produção; para realizar (vender) a produção ampliada, e, mais especificamente, a maior produção de meios de produção, os capitalistas precisam acumular ainda mais, adquirir maior volume de meios de produção; nesse sentido, a economia capitalista gira em círculos, círculos cada vez maiores. Rosa Luxemburgo, porém, acha que isto não pode ser assim, que os capitalistas não podem acumular capital apenas para realizarem uma parte (a parte não consumida) da mais-valia, porque assim fazendo os capitalistas estariam ampliando a produção e agravando cada vez mais o problema - como se não fosse esta a situação real, que se resolve com as crises econômicas (MIGLIOLI, 2004, p. 184).

Para Rosdolsky, "é lamentável que Rosa só soubesse defender a idéia da derrocada fazendo uma crítica - fundamentalmente errada - à teoria da reprodução de Marx” (2001, p. 408).

\section{CONSIDERAÇÕES FINAIS}

Rosa Luxemburgo comete um equívoco metodológico ao apresentar criticamente os argumentos de Marx. Contudo, isso não significa que ela tenha errado no que diz respeito ao funcionamento da dinâmica capitalista. Não há necessariamente um equívoco em Rosa Luxemburgo sobre a interpretação do funcionamento da sociedade capitalista. Simplesmente esses inúmeros fatores contribuíram para que em seu livro fosse dado demasiado peso ao papel dos mercados externos. Se estendermos um pouco mais a nossa análise, poderemos ver também que os limites que o próprio processo de acumulação elabora para si mesmo somente podem ser transpostos a partir de algum arranjo extracapitalista (como algum tipo de ajuda emergencial ou estrutural oferecida pelas instituições políticas, arranjos e acordos desenvolvidos no interior da classe capitalista, a criação de barreiras espaciais à entrada etc.) . Isso, contudo, não implica dizer que tais processos deverão ocorrer fundamentalmente sobre territórios de formação não capitalista.

O que Rosa Luxemburgo não considera é que o próprio capital elabora para si mesmo um fundo de reserva capitalista que pode ser consumido em tempos de crise. Sejam os gastos públicos (militares ou outros) ou mesmo a exploração de mercados externos não esgotam as possibilidades de arranjos reparadores; estes recursos não se elaboram como a única alternativa para a retomada de ciclos ascendentes na economia capitalista. Atingidos os limites da expansão/acumulação o vasto acervo de agremiações empresariais capitalistas servirá de reserva para novas e futuras expansões da parte mais resistente do capital atingido pela crise. Diante de constrangimentos que por vezes assolam as economias capitalistas, a solução pode ser encontrada também nas desvalorizações correntes de parte do capital ativo, com a falência de múltiplas empresas, o que implica frequentemente em liberações de ativos das mais diversas ordens, força de trabalho, terrenos, mercados consumidores ou matérias primas. Isso significa quase sempre a redução da concorrência na compra ou na venda dos fatores de capital e mercadorias, o que favorece a restauração das taxas de lucro. Essa possibilidade de resolução "interna" enreda-se num arranjo espacial reparador que não é carente de

Mercator - volume 9, número 18, 2010: jan./abr. 
territórios não-capitalistas. A desvalorização de arranjos capitalistas localizados em determinada áreas sugere uma reutilização ou um reingresso dessas porções territoriais nos ciclos mais recentes da acumulação capitalista.

Logo, se a obsessão de Luxemburgo, que encontra suas origens numa interpretação equivocada do papel desempenhado pelos esquemas de Marx, resultou quase sempre na necessidade de arranjos espaciais consumidores de territórios de formação não-capitalista, a alternativa a essa interpretação unívoca exige a consideração de resolução das crises capitalistas a partir da utilização de territórios já ocupados e transformados pelos processos de reprodução do capital.

\section{Referência Bibliográfica}

ARRIGHI, Giovanni. O Longo Século XX. São Paulo/Rio de Janeiro: Unesp/Contraponto. 1996. 408p. BRENNER, Robert. O Boom e a Bolha: os Estados Unidos na economia mundial. Rio de Janeiro: Record, 2003.

DAMIANI, Amélia L. A Propósito do Espaço e do Urbano: algumas hipóteses. Revista Cidades. Vol 1. No 1. 2004, pp. 79-96.

GRESPAN, J.L.S. O Negativo do Capital. São Paulo. Hucitec/FAPESP. 1999.

HARVEY, David. Los Límites del Capitalismo y la Teoría Marxista. México: Fondo de Cultura Econômica, 1990.

HARVEY, David. O Novo Imperialismo. São Paulo: Loyola, 2004.

HARVEY, David. A Produção Capitalista do Espaço. São Paulo: Anablume, 2005.

LENIN. O Desenvolvimento do Capitalismo na Russia. São Paulo: Abril Cultural. 1982.

LENIN. Imperialismo: fase superior do capitalismo. São Paulo: Global. 1979.

LUXEMBURGO, Rosa. A Acumulação do Capital. São Paulo: Nova Cultural. 1985.

MARX, K. O Capital. 1989.

MIGLIOLI, Jorge. Acumulação de Capital e Demanda Efetiva. São Paulo: Hucitec. 2004.

OLIVEIRA, Francisco de. Crítica à razão dualista. São Paulo: Boitempo. 2003. pp. 25-119.

ROBIRA, Rosa Tello. Áreas Metropolitanas: espaços colonizados. In: CARLOS, A.F.A. e CARRERAS, C. (Orgs.) Urbanização e Mundialização: estudos sobre a metrópole. São Paulo: Contexto, 2005, pp. 9-20.

ROSDOLSKY, Roman. Gênese e Estrutura de O Capital de Karl Marx. Rio de Janeiro: Eduerj/Contraponto, 2001, pp. 623.

SANTOS, César R. Simoni. Dos Negócios na Cidade à Cidade como Negócio: uma nova sorte de acumulação primitiva do espaço. Revista Cidades, Vol. 03, Nº 05, Janeiro-Junho de 2006. ISSN 1679-3625. pp. 101-122.

SANTOS, César R. Simoni. Da urbanização do território ao urbanismo da requalificação dos espaços centrais: . Geousp, 24, São Paulo: pp. 28-49.

SMITH, Neil. Gentrificação, a fronteira e a reestruturação do espaço urbano. GEOUSP, 21. São Paulo. 2007. pp. 15-31. 